Research paper

\title{
Longitudinal genotyping surveillance of Mycobacterium tuberculosis in an area with high tuberculosis incidence shows high transmission rate of the modern Beijing subfamily in Japan
}

\author{
Kaori Yamamoto $^{\mathrm{a}, \mathrm{b}}$, Shouhei Takeuchi ${ }^{\mathrm{c}}$, Junji Seto ${ }^{\mathrm{d}}$, Akira Shimouchi $^{\mathrm{e}}$, Jun Komukai ${ }^{\mathrm{f}}$, \\ Atsushi Hase ${ }^{\mathrm{b}}$, Hiromi Nakamura ${ }^{\mathrm{b}}$, Kaoru Umeda ${ }^{\mathrm{b}}$, Yuki Hirai ${ }^{\mathrm{b}}$, Kenji Matsumoto ${ }^{\mathrm{f}}$, \\ Jun Ogasawara ${ }^{\mathrm{b}}$, Takayuki Wada ${ }^{\mathrm{g}, \mathrm{h}, *}$, Taro Yamamoto ${ }^{\mathrm{a}, \mathrm{g}}$

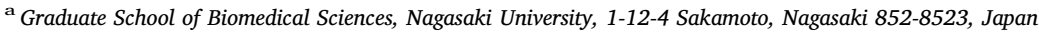 \\ ${ }^{\mathrm{b}}$ Division of Microbiology, Osaka Institute of Public Health, 8-34 Tojo-cho, Tennoji-ku, Osaka 543-0026, Japan \\ ${ }^{c}$ Department of Nutrition Science, Faculty of Nursing and Nutrition, University of Nagasaki, 1-1-1 Manabino, Nagayo, Nishisonogi, Nagasaki 851-2195, Japan \\ d Department of Microbiology, Yamagata Prefectural Institute of Public Health, 1-6-6 Toka-machi, Yamagata-shi, Yamagata 990-0031, Japan \\ ${ }^{\mathrm{e}}$ Nishinari Ward Office, 1-15-17 Taishi-cho, Nishinari-ku, Osaka 557-0002, Japan \\ ${ }^{f}$ Osaka City Public Health Center, 1-27-1000 Asahimachi, Abeno-ku, Osaka 545-0051, Japan \\ ${ }^{g}$ Department of International Health, Institute of Tropical Medicine, Nagasaki University, 1-12-4 Sakamoto, Nagasaki 852-8523, Japan \\ h School of Tropical Medicine and Global Health, Nagasaki University, 1-12-4 Sakamoto, Nagasaki 852-8523, Japan
}

A R T I C L E I N F O

\section{Keywords:}

Mycobacterium tuberculosis

Molecular epidemiology

Beijing family

VNTR

\begin{abstract}
A B S T R A C T
Tuberculosis (TB) is a severe and wide-spread infectious disease worldwide. The modern Beijing subfamily, one lineage of $M$. tuberculosis, reportedly has high pathogenicity and transmissibility. This study used a molecular epidemiological approach to investigate the transmissibility of the modern Beijing subfamily in the Airin area of Osaka City, Japan. During 2006-2016, we collected 596 M. tuberculosis clinical isolates in the Airin area, Osaka city, Japan. We analyzed the 24-locus variable number of tandem repeats typing optimized for the Beijing family of isolates, $M$. tuberculosis lineage, and patient epidemiological data. The proportion of the modern Beijing subfamily was significantly higher not only than previously obtained data for the Airin area: it was also higher than the nationwide in Japan. The rate of recent clusters, defined as a variable number of tandem repeats profile identified within two years, of the modern Beijing subfamily was significantly higher than that the rate of recent clusters of the ancient Beijing subfamily. Results suggest that TB control measures formulated with attention to the modern Beijing subfamily might be an important benchmark to understanding recent TB transmission in the area.
\end{abstract}

\section{Introduction}

Tuberculosis (TB), an infectious bacterial disease caused by Mycobacterium tuberculosis, affects millions worldwide: 10.4 million people developed TB in 2016; 1.7 million died (WHO, 2017). Based on the World Health Organization End TB Strategy, which set a goal to end the TB epidemic by 2035 (WHO, 2014), every country must undertake strong countermeasures to end $\mathrm{TB}$ in accordance with their own country-specific TB situation. In Japan, 13.9 TB cases/100,000 population were reported in 2016. The incidence was 7.2-32.8 among prefectures and major cities. Osaka city, the third most populated city in Japan (SBJ; Ministry of Internal Affairs and Communications, 2017), reported the highest $\mathrm{TB}$ incidence. This high incidence is partry attributable to the Airin area, a residential area of many homeless people and day laborers in the city, which showed abnormally high TB incidence (e.g., est. 395 cases $/ 100,000$ population in 2016) (Matsumoto, 2015). Homeless people have been regarded as a high-risk group of TB (Bamrah et al., 2013; Hayward and Coker, 2000; Korzeniewska-Kosela et al., 2015). Countermeasures for high-risk groups are necessary to reduce TB incidence especially in urban areas, finally leading to an end to TB worldwide.

The Beijing family, within the East Asian lineage, is spreading worldwide from its origin in eastern Asia (Glynn et al., 2006; Parwati et al., 2010). The family is distinct from the other three major phylogenetic lineages of $M$. tuberculosis because of its genetic differences (Gagneux et al., 2006). Furthermore, the Beijing family had a

\footnotetext{
* Corresponding author at: Department of International Health, Institute of Tropical Medicine, Nagasaki University, 1-12-4 Sakamoto, Nagasaki, Japan.

E-mail address: twada@nagasaki-u.ac.jp (T. Wada).
} 
genetically evolved lineage, defined as the modern Beijing subfamily. This evolved sublineage could be classified by several genetic markers such as an insertion of the IS6110 sequence into namely the NTF region (Kremer et al., 2004; Mokrousov et al., 2005) and single nucleotide polymorphisms (Filliol et al., 2006; Nakanishi et al., 2013; Tsolaki et al., 2005). Earlier studies have demonstrated that the modern Beijing subfamily might have higher virulence and transmissibility than the ancient Beijing subfamily, not only by epidemiological studies but also by an experimentary-based comparison (Hanekom et al., 2007a; Mokrousov et al., 2006; Ribeiro et al., 2014; van Laarhoven et al., 2013; Wada et al., 2009a). Considering prevention of the spread of TB, capturing the features of lineages and subfamilies is crucially important (Iwamoto et al., 2008, 2012; Langlois-Klassen et al., 2013; Luo et al., 2015; Maeda et al., 2014).

Reports of earlier studies have described that the modern Beijing subfamily is spreading globally (Bifani et al., 2002; Hanekom et al., 2007b; Iwamoto et al., 2012; Kato-Maeda et al., 2010; Mokrousov, 2013). In Japan, unlike the rest of the world, the ancient Beijing subfamily has been dominant (Iwamoto et al., 2008; Seto et al., 2015; Wada et al., 2009b), but the incidence of the modern Beijing subfamily is higher in younger age groups (Iwamoto et al., 2009; Seto et al., 2017). Therefore, distribution of the modern Beijing subfamily in Japan should be assessed adequately to call attention to the threat of TB expansion. For that purpose, elucidating the trend of the modern Beijing subfamily by dynamic tracking with long-term monitoring is fundamentally important.

Molecular epidemiology is an effective tool to discriminate isolates by genetic polymorphism and to verify infection links. Variable number of tandem repeats (VNTR) typing is a useful genotyping method to identify TB infections caused by the same isolate of $M$. tuberculosis (Supply et al., 2006). In Japan, $>75 \%$ of the clinical isolates belong to the Beijing family (Iwamoto et al., 2007; Murase et al., 2008; Wada

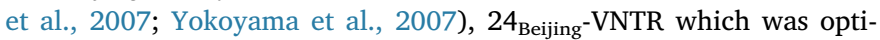
mized for discriminating Beijing family isolates by 24 loci subset (Iwamoto et al., 2007, 2012). Transmission among TB patients can be surmised when clinical isolates show an indistinguishable VNTR profile (hereinafter cluster). In spite of the straightforward and cost-effective concept as a routine TB surveillance (de Beer et al., 2013), estimation of ongoing outbreaks based on VNTR clustering often tends to be overestimated because of its low discriminatory power. Misclustering of epidemiologically unrelated isolates occurs partly because of nature of M. tuberculosis, which has the potential to remain dormant in the human body after infection and which can cause reactivation of past latent TB infection.

Because of such a dormant phase of TB, cluster formation observed by genotyping of clinical isolates is not always correspondent to recent TB transmission (Lillebaek et al., 2002; Seto et al., 2017). To evaluate $\mathrm{TB}$ onset after recent transmission, we must address the feature of latent TB infection. Sutherland (1968) reported from a follow-up survey of tuberculin-positive persons at 10 years that $78 \%$ of people developed TB within two years of an initial infection. According to the paper, some studies imply that cluster formation within two years can be regarded as a measure for considering recent TB transmission (de Vries et al., 2007; Kong et al., 2002; Langlois-Klassen et al., 2013).

The Airin area has extremely high TB incidence even in Osaka city, which has been the highest TB incidence district in Japan. Results of an earlier study implied that the modern Beijing subfamily in this area has high transmissibility and predicted that the detection rate would increase in the future (Wada et al., 2009a). This conjecture was based on the high transmissibility assumed by the modern Beijing subfamily. Further investigation must be done for verification. In this study, we performed a longitudinal population-based analysis; $24_{\text {Beijing }}$-VNTR typing and clustering analysis within two years. We aimed to clarify trends of the modern Beijing subfamily's subsequent decade in this area.

\section{Materials and method}

\subsection{Study setting}

The Airin area, occupying an area of $0.62 \mathrm{~km}^{2}$ in the northeastern part of Nishinari-ward of Osaka city, is known as Japan's largest urban poor area. In 2015, the area had 21,447 inhabitants, of whom $80.9 \%$ were male, $61.4 \%$ were elderly persons ( $\geq 60$ years of age), and $>$ $40.0 \%$ received welfare support. Approximately 12,000 residents were day laborers or the homeless: many working poor people in all over Japan tend to migrate to this area seeking temporary employment. They live in cheap apartments, night shelters, and cheap hotels, but they often become homeless.

\subsection{Study population}

We systematically collected $M$. tuberculosis clinical isolates from TB patients residing in the Airin area between January 2006 and December 2016. Demographic (sex, age) and clinical (site of disease, sputum smear status, and treatment history of TB) characteristics of the TB patients were connected with the isolates. We collected the isolates mainly from eight hospitals specializing in treatment of TB. This work was approved by the Ethics Committees of the Institute of Tropical Medicine, Nagasaki University (approval no. 170707172) and of Osaka Institute of Public Health (approval no. 1709-05).

\subsection{VNTR analysis}

M. tuberculosis isolates were suspended in $\mathrm{H}_{2} \mathrm{O}$ and heated at $95{ }^{\circ} \mathrm{C}$ for $10 \mathrm{~min}$. The supernatants of the heat-killed suspensions were used as PCR templates. $24_{\text {Beijing }}$-VNTR analysis was conducted according to reports of earlier studies (Iwamoto, et al., 2007, 2012). The size of amplified PCR fragments was found using a capillary electrophoresis system (SV1210; Hitachi High-Technologies Corp., Tokyo, Japan) or a genetic analyzer (Applied Biosystems 3500 genetic analyzer; Thermo Fisher Scientific Inc., Waltham, MA, USA.) with the GeneMapper program (ver. 5.0) (Iwamoto et al., 2012; Wada et al., 2007). We calculated the number of repeats in each locus from the size of amplified PCR fragments (Iwamoto, et al., 2007, 2012). All analyses were conducted at the Osaka Institute of Public Health.

\subsection{Clustering analysis}

A cluster was defined when two or more isolates showed indistinguishable $24_{\text {Beijing }}$ - VNTR profiles. We used the definition as an indicator of the probability that transmission occurred within the Airin area during the surveillance. Generally, epidemiological links between clustered patients are necessary to prove actual transmission (AllixBeguec et al., 2014; Seto et al., 2017). However, epidemiological information of patients in this area was difficult to obtain. Therefore, we introduced a definition of 'recent clusters' as an indicator of recent transmission. Because of this two-year time lag, only cases during 2008-2016 were used for the analysis of recent clusters. The rate of recent clusters in each year during 2008-2016 was calculated by dividing the total number of cases belonging to a recent cluster in one year by the number of cases for which VNTR analysis was conducted in that year (de Vries et al., 2007; Kong et al., 2002).

\subsection{Estimation of M. tuberculosis lineage}

We estimated the lineages of $M$. tuberculosis isolates using maximum a posteriori estimation with the $24_{\text {Beijing-VNTR profile, as described in }}$ an earlier report (Seto et al., 2015). We integrated the estimation results of four sub-lineages (i.e., ST11/26, STK, ST3, and ST25/19) as the ancient Beijing subfamily. We used the results of the modern Beijing subfamily, the ancient Beijing subfamily, and the non-Beijing family in 
this study. The population structure of $M$. tuberculosis lineages in the Airin area was compared with those found in earlier studies of this area (Wada et al., 2009a) and others throughout Japan (Seto et al., 2015).

\subsection{Statistical analysis}

Kruskal-Wallis testing was applied to compare cluster sizes among M. tuberculosis lineages. Adjusted residual analysis was used to assess the association between $M$. tuberculosis lineages and patient age groups, and to compare the rates of cluster formation among $M$. tuberculosis lineages. This analysis was also applied to compare the proportion of $M$. tuberculosis lineages found in earlier studies with those found in this study. Cochran-Armitage tests were applied to investigate the trends of annual rates in cases belonging to recent clusters. To ascertain the association between recent cluster formation and epidemiologic features, we used logistic regression analysis to calculate the odds ratio and $95 \%$ CIs. We applied multivariate logistic regression analysis using age groups and $M$. tuberculosis lineages as explanatory variables. We used backward stepwise for variable selection of multivariate analysis. We inferred results for which $p<0.05$ as statistically significant. All statistical analyses were conducted using software ( $\mathrm{R}$ ver. 3.4.3; $\mathrm{R}$ Foundation for Statistical Computing, Vienna, Austria).

\section{Results}

\subsection{Characteristics of the study population}

During 2006-2016, 1325 cases were registered in the Airin area, Osaka City, Japan; 810 of the cases were culture positive. We investigated 596 isolates (45.0\%) of the 1325 cases ( $73.6 \%$ of 810 culture positive cases) for this study.

The 596 patients had mean \pm SD age of $63.3 \pm 11.1$ (range 22-92) years. Most patients were male (579 patients, 97.1\%), Japanease (594 patients, 99.7\%) and undergoing primary TB treatment (527 patients, 88.4\%). Pulmonary TB (591 patients, 99.2\%) and sputum smear-positive (480 patients, $80.5 \%$ ) also had high proportions. Multidrug-resistant (MDR) patients were four (0.67\%). The profiles are typical of the population in this area.

\subsection{Distribution of M. tuberculosis lineages}

All of the 596 isolates were classified into three phylogenetic groups: the non-Beijing family (117 (19.6\%) isolates), the ancient Beijing subfamily (251 (42.1\%) isolates), and the modern Beijing subfamily $(228(38.3 \%)$ isolates) (Table 1$)$. It is noteworthy that no statistical significance by age group was found in the proportion of the modern Beijing subfamily.

\subsection{Overall TB transmission}

Genotyping analysis based on $24_{\text {Beijing }}$-VNTR typing revealed that $241(40.4 \%)$ out of the 596 isolates formed 56 clusters during

Table 1

Lineage of Mycobacterium tuberculosis by age groups in the Airin area, Osaka City, Japan, 2006-2016.

\begin{tabular}{lllll}
\hline $\begin{array}{l}\text { Patient age } \\
\text { group, y }\end{array}$ & $\begin{array}{l}\text { No. (\%) } \\
\text { patients }\end{array}$ & \multicolumn{2}{l}{ M. tuberculosis lineage, no. (\%) } \\
\cline { 3 - 5 } & & Non-Beijing & $\begin{array}{l}\text { Ancient } \\
\text { Beijing }\end{array}$ & $\begin{array}{l}\text { Modern } \\
\text { Beijing }\end{array}$ \\
\hline$\leq 49$ & $67(100)$ & $9(13.4)$ & $26(38.8)$ & $32(47.8)$ \\
$50-59$ & $148(100)$ & $38(25.7)^{\mathrm{a}}$ & $59(39.9)$ & $51(34.5)$ \\
$60-69$ & $214(100)$ & $39(18.2)$ & $86(40.2)$ & $89(41.6)$ \\
$\geq 70$ & $167(100)$ & $31(18.6)$ & $80(47.9)$ & $56(33.5)$ \\
\hline
\end{tabular}

${ }^{a}$ Significantly higher by Adjusted residual analysis $(p<0.05)$.

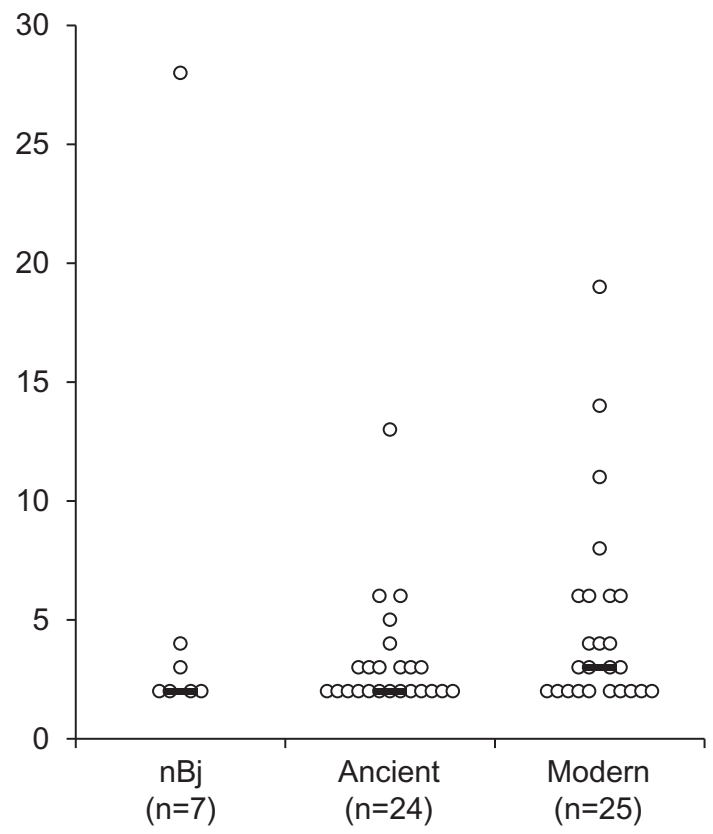

Fig. 1. Airin area, Osaka City, Japan, 2006-2016. Sizes of clusters formed by

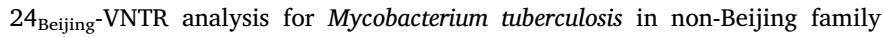
(nBj), the ancient Beijing subfamily (Ancient), and the modern Beijing subfamily (Modern): white circles represent clusters; black bars show median cluster size in each lineage.

2006-2016 (Supplementary Table S1, Fig. 1). We compared the proportion of cluster formation in cases of non-Beijing family, the ancient Beijing subfamily, and the modern Beijing subfamily. The modern Beijing subfamily cluster formation proportion was significantly higher than those of other strains (Table 2).

Among the 56 clusters, 5 clusters were formed by 10 or more isolates, were defined large cluster (Supplementary Table S1). Three of the five large clusters belonged to the modern Beijing subfamily (Fig. 1). These large clusters tended to be detected over nine years. Small clusters formed by $2-3$ cases were the most common in the respective groups, $71.4 \%$ (5/7 clusters) in non-Beijing, 79.2\% (19/24 clusters) in the ancient Beijing subfamily, and $56.0 \%$ (14/25 clusters) in the modern Beijing subfamily. Although no statistical significance was found ( $p=0.37$, Kruskal-Wallis test), the number of medium clusters formed in 4-9 cases were the highest in the modern Beijing subfamily.

\subsection{Recent TB transmission}

To estimate the frequency of recent transmission within the area, we used a definition of a recent cluster: indistinguishable VNTR profiles within two years before TB notification of a patient (de Vries et al., 2007; Kong et al., 2002). Rates of recent clusters calculated by year are presented in Fig. 2. A significant downward trend of recent cluster formation was observed during 2008-2016 ( $p<0.05$, Cochran-Armitage test).

Table 2

Proportion of clusters formed per genetic lineage in the Airin area, Osaka City, Japan, 2006-2016.

\begin{tabular}{llll}
\hline & $\begin{array}{l}\text { Non-Beijing, } \\
n=117\end{array}$ & $\begin{array}{l}\text { Ancient Beijing, } \\
n=251\end{array}$ & $\begin{array}{l}\text { Modern Beijing, } \\
n=228\end{array}$ \\
\hline $\begin{array}{l}\text { No. of clustered isolates } \\
\text { (\%) }\end{array}$ & $43(36.8)$ & $78(31.1)$ & $120(52.6)^{\mathrm{a}}$ \\
$\begin{array}{c}\text { No. of unique type } \\
\text { isolates (\%) }\end{array}$ & $74(63.2)$ & $173(68.9)^{\mathrm{a}}$ & $108(47.4)$ \\
\hline
\end{tabular}

${ }^{\text {a }}$ Significantly higher by Adjusted residual analysis $(p<0.05)$. 


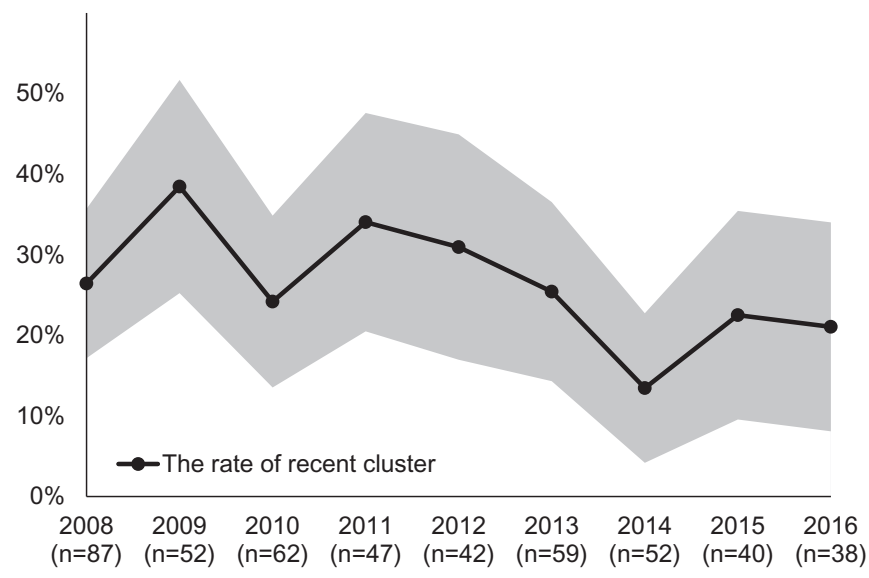

Fig. 2. Annual trends of recent cluster in the Airin area, Osaka City, Japan, 2008-2016: black lines show the rate of recent cluster in each year; gray bars represent $95 \%$ CI. Downward trend of the recent cluster rate was observed by Cochran-Armitage Test $(p<0.05)$.

Finally, risk factors for recent TB transmission were investigated using TB patient characteristics (Table 3). Patients 49 years old or younger had a significantly high odds ratio than patients 70 years old or older only in univariate analysis. In both univariate and multivariate analyses, sputum smear-positive cases showed a significantly higher odds ratio than sputum smear-negative cases. Also, the ancient Beijing subfamily had a significantly lower odds ratio than the modern Beijing subfamily, but statistical significance was not found between the modern Beijing subfamily and the non-Beijing family.

\section{Discussion}

In this study, we monitored transmission activities of the modern Beijing subfamily in the most prevalent TB area of Japan. We verified the trend of the modern Beijing subfamily along with genotyping approach and patients' epidemiological data, during more than a decade. In spite of recent reports describing the modern Beijing subfamily originated in northern China (Luo et al., 2015) has become dominant worldwide (Bifani et al., 2002; Hanekom et al., 2007b; Iwamoto et al., 2012; Kato-Maeda et al., 2010; Mokrousov, 2013; Yin et al., 2016), the transmissibility of the modern Beijing isolates remains unclear. In a basic research, the modern Beijing subfamily's survival strategy was implied that induced a lower level of proinflammatory cytokines compared with the ancient Beijing subfamily, could escape from the host immune system (van Laarhoven et al., 2013). Our findings indicate that the modern Beijing subfamily deserves attention as a threat of transmission in a high-TB incidence area.

Regarding the overall trend of TB in the Airin area, the rate of recent clusters has been decreasing (Fig. 2). Furthermore, VNTR clusters were less detected during the survey period in the latter half (21.4\%) (Supplementary Table S1). Those results indicate that recent isolates tended not to cause direct transmission in this area. The reduction of TB transmission may have been attributable to vigorous implementation of TB control for the area. Since 2001, the Osaka City Public Health Center has taken measures such as (1) patient supports daily Directly Observed Treatment: health staff observe TB patients to swallow TB medicine in front of them to make sure they are taking medicine daily, and (2) TB screening by chest $\mathrm{x}$-ray examination for residents to find new TB cases efficiently. The activities have been strengthened since 2012 to assure to provide free medical services and residences/rooms/beds for all TB patients and TB suspects in this area. As results, from 2013 to 2016, lost of follow-up rate reduced from $4.5 \%$ to $2.8 \%$, and proportion of patients detected by TB screening increased from $17.7 \%$ to $24.7 \%$ (data not shown). Furthermore, MDR rate of smear-positive patients reduced from $2.53 \%$ (35/1383) in 2001-2008 (Shimouchi et al., 2013) to $0.47 \%$ $(1 / 214)$ in 2013-2016 (data not shown). However in order to cope with transmission, early case finding of TB patients among the homeless and contact examination among residents of apartments should be further strengthened and expanded. Efforts to control TB in high incidence areas is indispensable to achieve the global eradication of TB (WHO, 2015). Molecular epidemiological monitoring is expected to become more important as the incidence rate decreases.

The modern Beijing subfamily was estimated as exhibiting high transmissibility in the Airin area from the viewpoint that the cluster size was regarded as indicating high propagation of isolates (Ypma et al., 2013). The largest cluster was composed of non-Beijing, but three of the five large clusters belonged to the modern Beijing subfamily.

Table 3

Risk factors for the recent transmission of M. tuberculosis in the Airin area, Osaka City, Japan, 2008-2016.

\begin{tabular}{|c|c|c|c|c|}
\hline \multirow[t]{2}{*}{ Patient characteristic } & \multicolumn{2}{|l|}{$\begin{array}{l}24_{\text {Beijing }} \text {-VNTR profile, } \\
\text { no. }(\%)\end{array}$} & \multicolumn{2}{|l|}{ Odds ratio $(95 \% \mathrm{Cl})^{\mathrm{a}}$} \\
\hline & Did not form recent clusters, $n=353$ & Recent clusters, $n=126$ & Univariate & Multivariate $^{\mathrm{b}}$ \\
\hline \multicolumn{5}{|l|}{ Age group } \\
\hline$\leq 49$ & $36(10.2)$ & $19(15.1)$ & $2.04(1.03-4.05)$ & $-{ }^{c}$ \\
\hline $50-59$ & $71(20.1)$ & $31(24.6)$ & $1.69(0.94-3.02)$ & - \\
\hline $60-69$ & $130(36.8)$ & $46(36.5)$ & $1.37(0.81-2.31)$ & - \\
\hline$\geq 70$ & $116(32.9)$ & $30(23.8)$ & 1.0 & - \\
\hline \multicolumn{5}{|l|}{ Sex } \\
\hline Female & $9(2.5)$ & $6(4.8)$ & $1.91(0.67-5.48)$ & - \\
\hline Male & $344(97.5)$ & $120(95.2)$ & 1.0 & - \\
\hline \multicolumn{5}{|l|}{ Disease site } \\
\hline Pulmonary, sputum smear-positive & $276(78.2)$ & $110(87.3)$ & $2.14(1.16-3.94)$ & $2.21(1.18-4.12)$ \\
\hline Pulmonary, sputum smear-negative & $75(21.2)$ & $14(11.1)$ & 1.0 & 1.0 \\
\hline Extrapulmonary & $2(0.6)$ & $2(1.6)$ & $5.36(0.70-41.25)$ & $4.11(0.52-32.51)$ \\
\hline \multicolumn{5}{|l|}{ Treatment history } \\
\hline Primary & $311(88.1)$ & $116(92.1)$ & $1.57(0.76-3.22)$ & $1.71(0.81-3.61)$ \\
\hline Retreatment & $42(11.9)$ & $10(7.9)$ & 1.0 & 1.0 \\
\hline \multicolumn{5}{|l|}{ M. tuberculosis lineage } \\
\hline Non-Beijing & $66(18.7)$ & $24(19.0)$ & $0.62(0.36-1.08)$ & $0.62(0.36-1.10)$ \\
\hline Ancient Beijing & $171(48.4)$ & $34(27.0)$ & $0.34(0.21-0.55)$ & $0.34(0.21-0.55)$ \\
\hline Modern Beijing & $116(32.9)$ & $68(54.0)$ & 1.0 & 1.0 \\
\hline
\end{tabular}

${ }^{\text {a }}$ Cls that do not overlap the null value of odds ratio $=1$ are shown in bold.

b Adjusted for the other factors used in the multivariate model.

${ }^{\text {c }}$ No variables. 
Table 4

Distribution of $M$. tuberculosis lineages among different study population.

\begin{tabular}{|c|c|c|c|c|c|}
\hline \multirow[t]{2}{*}{ Area } & \multirow[t]{2}{*}{ Study period } & \multirow[t]{2}{*}{$n(\%)$} & \multicolumn{3}{|c|}{ No. of isolates (\%) } \\
\hline & & & Non-Beijing & $\begin{array}{l}\text { Ancient } \\
\text { Beijing }\end{array}$ & $\begin{array}{l}\text { Modern } \\
\text { Beijing }\end{array}$ \\
\hline $\begin{array}{c}\text { Previous study } \\
\text { of Airin } \\
\text { area }^{\mathrm{a}}\end{array}$ & $2002-2004$ & $\begin{array}{l}274 \\
(100)\end{array}$ & $61(22.3)$ & $\begin{array}{l}137 \\
(50.0)^{c}\end{array}$ & $76(27.7)$ \\
\hline $\begin{array}{l}\text { All over } \\
\text { Japan }^{\text {b }}\end{array}$ & 2004-2013 & $\begin{array}{l}1245 \\
(100)\end{array}$ & $310(24.9)^{\mathrm{d}}$ & $\begin{array}{l}716 \\
(57.5)^{d}\end{array}$ & $219(17.6)$ \\
\hline This study & $2006-2016$ & $\begin{array}{l}596 \\
(100)\end{array}$ & 117 (19.6) & $251(42.1)$ & $\begin{array}{l}228 \\
(38.3)^{\mathrm{e}}\end{array}$ \\
\hline
\end{tabular}

a Wada et al. (2009a,b).

b Seto and Wada et al. (2015).

c $p<0.05$, Adjusted residual analysis between This study or Previous study of Airin area.

${ }^{\mathrm{d}} p<0.05$, Adjusted residual analysis between This study or All over Japan.

e $p<0.05$, Adjusted residual analysis between This study or All over Japan.

Furthermore, although no significant difference was observed, the median cluster size of the modern Beijing subfamily was larger than that of the other lineages (Fig. 1). One aspect of the social background in the Airin area is that low-income people who have difficulty finding jobs in their hometown immigrate from throughout Japan. Further efforts to incorporate patient information into research design must be undertaken to resolve whether increase of the modern Beijing subfamily is related to the inflow of people or stable circulation of the subfamily within the area.

Expansion of the modern Beijing subfamily was not limited to certain age groups in our setting (Table 1). In earlier studies, the modern Beijing subfamily was found to be significantly predominant in younger age groups in Japan (Iwamoto et al., 2009; Seto et al., 2017). In contrast to that tendency, the subfamily was isolated from TB patients in the Airin area irrespective of age groups in this study (Table 1). The result might be related to a common behavior of persons living in this area; they usually do not belong to a specific community and spend long periods in close and overcrowded spaces (e.g., shelters, libraries, and resting places) irrespective of their age.

Our results suggest that the modern Beijing subfamily affects recent TB transmission in the Airin area. Multivariate analysis for recent cluster formation showed the modern Beijing subfamily cause more recent transmission than the ancient Beijing subfamily (Table 3). Although the same tendency was not confirmed between the non-Beijing family and the modern Beijing subfamily, the largest cluster of the nonBeijing family (Supplementary Table S1) might influence the non-significant result. Except for that case, the modern Beijing subfamily was constantly transmitted within the area. This assumption would also be suggested by the proportion of the modern Beijing subfamily in the Airin area was clearly increased over previous studies (Wada et al., 2009a) and higher than the nationwide data in Japan (Seto et al., 2015) (Table 4). This result supports an earlier report describing that the modern Beijing subfamily can show high transmission activity among a highly dense population (Hanekom et al., 2007a).

Our study had several potential limitations. First, all cases in the Airin area during the monitored period couldn't be investigated in this study. It causes overlooking of recent transmission which should be detected as precise as possible. In this point, regarding culture negative cases, the affects may be limited because such cases were not involved in active TB transmission mainly. Culture positive clinical isolates should be systematically collected to reduce artificial bias on isolates collection. Second, we couldn't thoroughly investigate the transmission routes of patients with the same clusters, although $24_{\text {Beijing }}$-VNTR typing method was incorporated in this study to reduce false clusters. Currently, molecular epidemiology of $M$. tuberculosis has shifted from genotyping-based methods to whole-genome analysis (Jajou et al.,
2018; Walker et al., 2013). The novel technical improvement enables us to estimate direct transmission routes only by genome sequences of clinical isolates much more precisely, which will provide additional advantage for isolates-based analysis for TB countermeasure.

\section{Conclusion}

A longitudinal molecular epidemiologic monitoring based on VNTR clusters within two years revealed that transmission of TB was decreasing in the Airin area. However, TB incidence in this area was still high (395 cases/100,000 population in 2016) and active transmission still occurred continuously. Under such circumstances, the modern Beijing subfamily was confirmed as a risk factor of recent TB transmissions compared with other lineages in the Airin area. Furthermore, the proportion of this subfamily was found to be increasing in this area. These results suggest that the modern Beijing subfamily represents an epidemic threat in areas with high TB incidence. It might require careful consideration of further strengthening and expansion for TB control measures.

\section{Funding}

This work was supported by JSPS KAKENHI Grants No. 26893338 and 17H04136. This study was also supported by the Japan Agency for Medical Research and Development (AMED) (JP18fk0108063) partly.

\section{Acknowledgments}

We would like to thank Osaka City Public Health Center staff and Osaka City Nishinari Ward Health and Welfare Center staff for data and isolate collections.

\section{Appendix A. Supplementary data}

Supplementary data to this article can be found online at https:// doi.org/10.1016/j.meegid.2018.09.014.

\section{References}

Allix-Beguec, C., Wahl, C., Hanekom, M., Nikolayevskyy, V., Drobniewski, F., Maeda, S., Campos-Herrero, I., Mokrousov, I., Niemann, S., Kontsevaya, I., Rastogi, N., Samper, S., Sng, L.H., Warren, R.M., Supply, P., 2014. Proposal of a consensus set of hypervariable mycobacterial interspersed repetitive-unit-variable-number tandem-repeat loci for subtyping of Mycobacterium tuberculosis Beijing isolates. J. Clin. Microbiol. 52, 164-172.

Bamrah, S., Yelk Woodruff, R.S., Powell, K., Ghosh, S., Kammerer, J.S., Haddad, M.B. 2013. Tuberculosis among the homeless, United States, 1994-2010. Int. J. Tuberc. Lung. Dis. 17, 1414-1419.

Bifani, P.J., Mathema, B., Kurepina, N.E., Kreiswirth, B.N., 2002. Global dissemination of the Mycobacterium tuberculosis W-Beijing family strains. Trends Microbiol. 10, 45-52.

de Beer, J.L., van Ingen, J., de Vries, G., Erkens, C., Sebek, M., Mulder, A., Sloot, R., van den Brandt, A.M., Enaimi, M., Kremer, K., Supply, P., van Soolingen, D., 2013. Comparative study of IS6110 restriction fragment length polymorphism and variablenumber tandem-repeat typing of Mycobacterium tuberculosis isolates in the Netherlands, based on a 5-year nationwide survey. J. Clin. Microbiol. 51, 1193-1198.

de Vries, G., van Hest, R.A., Richardus, J.H., 2007. Impact of mobile radiographic screening on tuberculosis among drug users and homeless persons. Am. J. Respir. Crit. Care Med. 176, 201-207.

Filliol, I., Motiwala, A.S., Cavatore, M., Qi, W., Hazbon, M.H., Bobadilla Del Valle, M., Fyfe, J., Garcia-Garcia, L., Rastogi, N., Sola, C., Zozio, T., Guerrero, M.I., Leon, C.I., Crabtree, J., Angiuoli, S., Eisenach, K.D., Durmaz, R., Joloba, M.L., Rendon, A., Sifuentes-Osornio, J., Ponce De Leon, A., Cave, M.D., Fleischmann, R., Whittam, T.S., Alland, D., 2006. Global phylogeny of Mycobacterium tuberculosis based on single nucleotide polymorphism (SNP) analysis: insights into tuberculosis evolution, phylogenetic accuracy of other DNA fingerprinting systems, and recommendations for a minimal standard SNP set. J. Bacteriol. 188, 759-772.

Gagneux, S., Deriemer, K., Van, T., Kato-Maeda, M., de Jong, B.C., Narayanan, S., Nicol, M., Niemann, S., Kremer, K., Gutierrez, M.C., Hilty, M., Hopewell, P.C., Small, P.M., 2006. Variable host-pathogen compatibility in Mycobacterium tuberculosis. Proc. Natl. Acad. Sci. U. S. A. 103, 2869-2873.

Glynn, J.R., Kremer, K., Borgdorff, M.W., Pujades-Rodriguez, M., van Soolingen, D., Tuberculosis, European Concerted Action on New Generation Genetic Markers and Techniques for the Epidemiology and Control of Tuberculosis, 2006. Beijing/W genotype Mycobacterium tuberculosis and drug resistance. Emerg. Infect. Dis. 12, 
$736-743$

Hanekom, M., van der Spuy, G.D., Gey Van Pittius, N.C., McEvoy, C.R., Ndabambi, S.L., Victor, T.C., Hoal, E.G., van Helden, P.D., Warren, R.M., 2007a. Evidence that the spread of Mycobacterium tuberculosis strains with the Beijing genotype is human population dependent. J. Clin. Microbiol. 45, 2263-2266.

Hanekom, M., van der Spuy, G.D., Streicher, E., Ndabambi, S.L., McEvoy, C.R., Kidd, M., Beyers, N., Victor, T.C., van Helden, P.D., Warren, R.M., 2007b. A recently evolved sublineage of the Mycobacterium tuberculosis Beijing strain family is associated with an increased ability to spread and cause disease. J. Clin. Microbiol. 45, 1483-1490.

Hayward, A.C., Coker, R.J., 2000. Could a tuberculosis epidemic occur in London as it did in New York? Emerg. Infect. Dis. 6, 12-16.

Iwamoto, T., Yoshida, S., Suzuki, K., Tomita, M., Fujiyama, R., Tanaka, N., Kawakami, Y., Ito, M., 2007. Hypervariable loci that enhance the discriminatory ability of newly proposed 15-loci and 24-loci variable-number tandem repeat typing method on Mycobacterium tuberculosis strains predominated by the Beijing family. FEMS Microbiol. Lett. 270, 67-74.

Iwamoto, T., Yoshida, S., Suzuki, K., Wada, T., 2008. Population structure analysis of the Mycobacterium tuberculosis Beijing family indicates an association between certain sublineages and multidrug resistance. Antimicrob. Agents Chemother. 52, 3805-3809.

Iwamoto, T., Fujiyama, R., Yoshida, S., Wada, T., Shirai, C., Kawakami, Y., 2009. Population structure dynamics of Mycobacterium tuberculosis Beijing strains during past decades in Japan. J. Clin. Microbiol. 47, 3340-3343.

Iwamoto, T., Grandjean, L., Arikawa, K., Nakanishi, N., Caviedes, L., Coronel, J., Sheen, P., Wada, T., Taype, C.A., Shaw, M.A., Moore, D.A., Gilman, R.H., 2012. Genetic diversity and transmission characteristics of Beijing family strains of Mycobacterium tuberculosis in Peru. PLoS One 7, e49651.

Jajou, R., de Neeling, A., van Hunen, R., de Vries, G., Schimmel, H., Mulder, A., Anthony, R., van der Hoek, W., van Soolingen, D., 2018. Epidemiological links between tuberculosis cases identified twice as efficiently by whole genome sequencing than conventional molecular typing: a population-based study. PLoS One 13, e0195413.

Kato-Maeda, M., Kim, E.Y., Flores, L., Jarlsberg, L.G., Osmond, D., Hopewell, P.C., 2010. Differences among sublineages of the East-Asian lineage of Mycobacterium tuberculosis in genotypic clustering. Int. J. Tuberc. Lung. Dis. 14, 538-544.

Kong, P.M., Tapy, J., Calixto, P., Burman, W.J., Reves, R.R., Yang, Z., Cave, M.D., 2002. Skin-test screening and tuberculosis transmission among the homeless. Emerg. Infect. Dis. 8, 1280-1284.

Korzeniewska-Kosela, M., Kus, J., Lewandowska, K., Siemion-Szczesniak, I., 2015. Tuberculosis in homeless persons in Poland. Przegl. Epidemiol. 69, 445-451, 575-580.

Kremer, K., Glynn, J.R., Lillebaek, T., Niemann, S., Kurepina, N.E., Kreiswirth, B.N., Bifani, P.J., van Soolingen, D., 2004. Definition of the Beijing/W lineage of Mycobacterium tuberculosis based on genetic markers. J. Clin. Microbiol. 42, 4040-4049.

Langlois-Klassen, D., Senthilselvan, A., Chui, L., Kunimoto, D., Saunders, L.D., Menzies, D., Long, R., 2013. Transmission of Mycobacterium tuberculosis Beijing strains, Alberta, Canada, 1991-2007. Emerg. Infect. Dis. 19, 701-711.

Lillebaek, T., Dirksen, A., Baess, I., Strunge, B., Thomsen, V.O., Andersen, A.B., 2002 Molecular evidence of endogenous reactivation of Mycobacterium tuberculosis after 33 years of latent infection. J. Infect. Dis. 185, 401-404.

Luo, T., Comas, I., Luo, D., Lu, B., Wu, J., Wei, L., Yang, C., Liu, Q., Gan, M., Sun, G., Shen, X., Liu, F., Gagneux, S., Mei, J., Lan, R., Wan, K., Gao, Q., 2015. Southern East Asian origin and coexpansion of Mycobacterium tuberculosis Beijing family with Han Chinese. Proc. Natl. Acad. Sci. U. S. A. 112, 8136-8141.

Maeda, S., Hang, N.T., Lien, L.T., Thuong, P.H., Hung, N.V., Hoang, N.P., Cuong, V.C. Hijikata, M., Sakurada, S., Keicho, N., 2014. Mycobacterium tuberculosis strains spreading in Hanoi, Vietnam: Beijing sublineages, genotypes, drug susceptibility patterns, and host factors. Tuberculosis (Edinb) 94, 649-656.

Matsumoto, K., 2015. Importance of health care for the eradication of tuberculosis - efforts implemented in Nishinari Ward, Osaka City. Kekkaku 90, 715-722 (Osaka City).

Mokrousov, I., 2013. Insights into the origin, emergence, and current spread of a successful Russian clone of Mycobacterium tuberculosis. Clin. Microbiol. Rev. 26, 342-360.

Mokrousov, I., Ly, H.M., Otten, T., Lan, N.N., Vyshnevskyi, B., Hoffner, S., Narvskaya, O., 2005. Origin and primary dispersal of the Mycobacterium tuberculosis Beijing genotype: clues from human phylogeography. Genome Res. 15, 1357-1364.

Mokrousov, I., Jiao, W.W., Sun, G.Z., Liu, J.W., Valcheva, V., Li, M., Narvskaya, O., Shen, A.D., 2006. Evolution of drug resistance in different sublineages of Mycobacterium tuberculosis Beijing genotype. Antimicrob. Agents Chemother. 50, 2820-2823.

Murase, Y., Mitarai, S., Sugawara, I., Kato, S., Maeda, S., 2008. Promising loci of variable numbers of tandem repeats for typing Beijing family Mycobacterium tuberculosis. J. Med. Microbiol. 57, 873-880.

Nakanishi, N., Wada, T., Arikawa, K., Millet, J., Rastogi, N., Iwamoto, T., 2013. Evolutionary robust SNPs reveal the misclassification of Mycobacterium tuberculosis
Beijing family strains into sublineages. Infect. Genet. Evol. 16, 174-177.

Parwati, I, van Crevel, R., van Soolingen, D., 2010. Possible underlying mechanisms for successful emergence of the Mycobacterium tuberculosis Beijing genotype strains. Lancet Infect. Dis. 10, 103-111.

Ribeiro, S.C., Gomes, L.L., Amaral, E.P., Andrade, M.R., Almeida, F.M., Rezende, A.L., Lanes, V.R., Carvalho, E.C., Suffys, P.N., Mokrousov, I., Lasunskaia, E.B., 2014. Mycobacterium tuberculosis strains of the modern sublineage of the Beijing family are more likely to display increased virulence than strains of the ancient sublineage. J. Clin. Microbiol. 52, 2615-2624.

SBJ, Ministry of Internal Affairs and Communications, J, 2017. Statistical Handbook of Japan 2017. http://www.stat.go.jp/english/data/handbook/index.htm (accessed 27 March 2018).

Seto, J., Wada, T., Iwamoto, T., Tamaru, A., Maeda, S., Yamamoto, K., Hase, A., Murakami, K., Maeda, E., Oishi, A., Migita, Y., Yamamoto, T., Ahiko, T., 2015. Phylogenetic assignment of Mycobacterium tuberculosis Beijing clinical isolates in Japan by maximum a posteriori estimation. Infect. Genet. Evol. 35, 82-88.

Seto, J., Wada, T., Suzuki, Y., Ikeda, T., Mizuta, K., Yamamoto, T., Ahiko, T., 2017. Mycobacterium tuberculosis transmission among elderly persons, Yamagata Prefecture, Japan, 2009-2015. Emerg. Infect. Dis. 23, 448-455.

Shimouchi, A., Ohkado, A., Matsumoto, K., Komukai, J., Yoshida, H., Ishikawa, N., 2013. Strengthened tuberculosis control programme and trend of multidrug resistant tuberculosis rate in Osaka City, Japan. WPSAR 4 (1).

Supply, P., Allix, C., Lesjean, S., Cardoso-Oelemann, M., Rusch-Gerdes, S., Willery, E., Savine, E., de Haas, P., van Deutekom, H., Roring, S., Bifani, P., Kurepina, N., Kreiswirth, B., Sola, C., Rastogi, N., Vatin, V., Gutierrez, M.C., Fauville, M., Niemann, S., Skuce, R., Kremer, K., Locht, C., van Soolingen, D., 2006. Proposal for standardization of optimized mycobacterial interspersed repetitive unit-variable-number tandem repeat typing of Mycobacterium tuberculosis. J. Clin. Microbiol. 44, 4498-4510.

Sutherland, I., 1968. The ten-year incidence of clinical tuberculosis following "conver sion". In: 2550 individuals aged 14 to 19 years. TSRU Progress Report.

Tsolaki, A.G., Gagneux, S., Pym, A.S., Goguet De La Salmoniere, Y.O., Kreiswirth, B.N., Van Soolingen, D., Small, P.M., 2005. Genomic deletions classify the Beijing/W strains as a distinct genetic lineage of Mycobacterium tuberculosis. J. Clin. Microbiol. 43, 3185-3191.

van Laarhoven, A., Mandemakers, J.J., Kleinnijenhuis, J., Enaimi, M., Lachmandas, E., Joosten, L.A., Ottenhoff, T.H., Netea, M.G., van Soolingen, D., van Crevel, R., 2013. Low induction of proinflammatory cytokines parallels evolutionary success of modern strains within the Mycobacterium tuberculosis Beijing genotype. Infect. Immun. 81, 3750-3756.

Wada, T., Maeda, S., Hase, A., Kobayashi, K., 2007. Evaluation of variable numbers of tandem repeat as molecular epidemiological markers of Mycobacterium tuberculosis in Japan. J. Med. Microbiol. 56, 1052-1057.

Wada, T., Fujihara, S., Shimouchi, A., Harada, M., Ogura, H., Matsumoto, S., Hase, A., 2009a. High transmissibility of the modern Beijing Mycobacterium tuberculosis in homeless patients of Japan. Tuberculosis (Edinb) 89, 252-255.

Wada, T., Iwamoto, T., Maeda, S., 2009b. Genetic diversity of the Mycobacterium tuberculosis Beijing family in East Asia revealed through refined population structure analysis. FEMS Microbiol. Lett. 291, 35-43.

Walker, T.M., Ip, C.L., Harrell, R.H., Evans, J.T., Kapatai, G., Dedicoat, M.J., Eyre, D.W., Wilson, D.J., Hawkey, P.M., Crook, D.W., Parkhill, J., Harris, D., Walker, A.S., Bowden, R., Monk, P., Smith, E.G., Peto, T.E., 2013. Whole-genome sequencing to delineate Mycobacterium tuberculosis outbreaks: a retrospective observational study. Lancet Infect. Dis. 13, 137-146.

World Health Organization, 2014. The End TB Strategy. Global strategy and targets for tuberculosis prevention, care and control after. 2015. http://www.who.int/tb/ strategy/End_TB_Strategy.pdf (accessed 27 Mar 2018).

World Health Organization, 2015. Guidelines on the management of latent tuberculosis infection. http://www.who.int/tb/publications/latent-tuberculosis-infection/en/ (accessed 27 Aug 2018).

World Health Organization, 2017. Tuberculosis (TB). Global Tuberculosis Report 2017. http://www.who.int/tb/publications/global_report/en/ (accessed 27 Mar 2018).

Yin, Q.Q., Liu, H.C., Jiao, W.W., Li, Q.J., Han, R., Tian, J.L., Liu, Z.G., Zhao, X.Q., Li, Y.J., Wan, K.L., Shen, A.D., Mokrousov, I., 2016. Evolutionary history and ongoing transmission of phylogenetic sublineages of Mycobacterium tuberculosis Beijing genotype in China. Sci. Rep. 6, 34353.

Yokoyama, E., Kishida, K., Uchimura, M., Ichinohe, S., 2007. Improved differentiation of Mycobacterium tuberculosis strains, including many Beijing genotype strains, using a new combination of variable number of tandem repeats loci. Infect. Genet. Evol. 7, 499-508.

Ypma, R.J., Altes, H.K., van Soolingen, D., Wallinga, J., van Ballegooijen, W.M., 2013. A sign of superspreading in tuberculosis: highly skewed distribution of genotypic cluster sizes. Epidemiology 24, 395-400. 